\title{
Nephrolithiasis in the Obese Patient
}

\author{
Claire Kelly $^{1} \cdot$ Robert M. Geraghty ${ }^{2} \cdot$ Bhaskar K. Somani $^{2}$
}

Published online: 18 May 2019

(C) The Author(s) 2019

\begin{abstract}
Purpose of Review The link between metabolic syndrome (MetS)/obesity and kidney stone disease (KSD) has gained importance over recent years due to the increasing prevalence and healthcare burden worldwide. This review analyses the literature exploring the link between MetS/obesity and KSD and the impact that obesity has on KSD management.

Recent Findings Metabolic syndrome has been shown to increase an individual's risk of developing kidney stone disease, with insulin resistance forming a core component of the pathophysiology. The body habitus of an individual also influences the type of intervention that is most appropriate, with flexible ureteroscopy increasingly being the preferred option in obese patients.

Summary It is important for urologists to consider the features of metabolic syndrome to effectively manage episodes of KSD in obese patients. In addition, better quality evidence is required to effectively compare different treatment options in this group of patients.
\end{abstract}

Keywords Metabolic syndrome $\cdot$ Kidney stone disease $\cdot$ Insulin resistance $\cdot$ Shock wave lithotripsy Flexible ureteroscopy Percutaneous nephrolithotomy · RIRS · URS · Obese

\section{Introduction}

Kidney stone disease (KSD) is a condition resulting from precipitation of urinary solutes to form solid stones within the urinary tract. Whilst it is possible for individuals to form and pass these stones remaining asymptomatic [1], the majority of stones require costly surgical treatment. KSD prevalence is rising and therefore it is increasing the healthcare burden worldwide $[2,3]$.

One of the factors thought to be contributing to the increasing prevalence is the concurrent increase in obesity rates, with previous studies showing a demonstrably increased risk of KSD in obese populations [4]. Obesity, defined as having a body mass index of $\geq 30 \mathrm{~kg} \mathrm{~m}^{-2}$, is one of the components of metabolic syndrome (MetS) [5]. This review will aim to look

This article is part of the Topical Collection on Endourology

Robert M. Geraghty

r.geraghty@ soton.ac.uk

1 University of Southampton, Southampton, UK

2 Department of Urology, University Hospital Southampton, Tremona Road, Southampton SO16 6YD, UK at recent research into the role obesity and MetS has in the development of KSD, and the implications this has for the treatment and management of the disease.

\section{Obesity and Metabolic Syndrome}

There will be a projected 11 million more obese adults in the UK by 2030 compared with 2010, attributing to an increase of $£ 2$ billion per annum in healthcare costs [6]. Obesity is a feature strongly associated with the diagnosis of MetS, with the majority of individuals with MetS having a BMI of $>$ $30 \mathrm{~kg} / \mathrm{m}^{2}$ [2-9]. The classification and understanding of MetS have developed over the last few decades. The main theme across various classifications is insulin resistance, which is likely to be a sequela of increasing adiposity. The current definition, described by the NCEP ATP III (National Cholesterol Education Programme Adult Treatment Panel III) criteria [7], requires three of five components to be present: obesity, hypertriglyceridemia, reduced high-density lipoprotein (HDL), hypertension and hyperglycaemia [7] (see Table 1). The current pathogenesis model for MetS hypothesises that a positive caloric balance is the precipitating factor, and restricting calorie intake even in the continuing state of obesity may reverse MetS $[10,11]$. 
Table 1 The NCEP ATP III diagnostic criteria of metabolic syndrome
Waist circumference

HDL concentration

Blood pressure

Fasting glucose
Triglycerides
Males $>102 \mathrm{~cm}$

Females $>88 \mathrm{~cm}$

$\geq 150 \mathrm{mg} / \mathrm{dL}$

Males $\leq 40 \mathrm{mg} / \mathrm{dL}$ Females $\leq 50 \mathrm{mg} / \mathrm{dL}$

$\geq 130 \mathrm{mmHg}$ systolic and/ or $\geq 85 \mathrm{mmHg}$ diastolic $\geq 100 \mathrm{mg} / \mathrm{dL}$

\section{Nephrolithiasis and Metabolic Syndrome}

KSD is a relatively common disorder, with the lifetime prevalence of up to $14 \%$, and this rate is increasing [1, $3,12,13]$. There are many different compositions of stones, with calcium oxalate and calcium phosphate stones being the most common at around $80 \%$ and urate stones forming at approximately $10 \%$. Stones formed from struvite and cystine account for approximately $2 \%$ and $1 \%$, respectively, and are understood to have a different pathogenesis from calcium and urate stones [14].

\section{Obesity}

Multiple cohort studies have concluded that individuals who are considered obese are more at risk of developing kidney stones $[15,16]$, and in particular increased levels of visceral adiposity have been associated with uric acid nephrolithiasis [17]. The National Health and Nutrition Examination Survey (NHANES) cross-sectional study showed that KSD was more likely in obese individuals $(11.2 \%, 95 \%$ CI $10.0-12.3 \%)$ in comparison to normal-weight individuals $(6.1 \%, 95 \%$ CI $4.8-$ $7.4 \%, p<0.001)$ [18]. Multivariate analysis of the US National Inpatient Sample database showed that obesity significantly increased the likelihood of a previous stone event (OR 1.22, 95\% CI 1.20-1.23, p<0.001) [19]. Notably, obesity appeared to have a stronger impact of the likelihood of women developing KSD (OR 1.35, 95\% CI 1.20-1.23, $p<0.001)$ in comparison to obese males $(1.04,95 \% \mathrm{CI}$ $1.02-1.06, p<0.001)$ [19].

Not only was obesity linked with an increased risk of developing KSD, but it also influenced the composition of the stones. Whilst calcium oxalate still composed the majority of stones formed, as BMI increases, the proportion of uric acid stones increases. One retrospective analysis reported that uric acid stones formed $23.9 \%$ of stones in morbidly obese patients in contrast to $8.9 \%$ in the normalweight patients [20]. In addition to obesity, hypertension and diabetes mellitus were positively associated with urate stone formation, with a concurrent decrease in calcium phosphate stone formation [20].

\section{Insulin Resistance}

Insulin resistance is a condition that is characterised by a lack of response to circulating insulin, resulting in the inability of the body to carry out appropriate glucose uptake into the desired target tissues [21]. Both poor glycaemic control and insulin resistance have been shown to increase the odds of an individual developing kidney stones [22]. Individuals with $\mathrm{HbA}_{1} \mathrm{c}>6.5 \%$, as a marker for poor glycaemic control, had higher odds of developing kidney stones (OR 2.82, 95\% CI 1.68-3.12). Those with elevated HOMAR-IR, an indicator of insulin resistance, also had increased odds of developing kidney stones (OR 2.11, 95\% CI 1.62-2.71) [22]. Kabeya et al. demonstrated that deranged glucose handling was associated with a higher likelihood of stone formation (adjusted OR 1.53, 95\% CI 1.08-2.17) [21]. Poor glycaemic control is associated with increased levels of uric acid, calcium and oxalate in the urine with associated reduction in ammonia and citrate excretion and urinary acidification. Combined, these contribute to an increased risk of KSD [23, 24].

\section{Hypertension}

There is conflicting evidence for the correlation of hypertension (HT) and KSD. One study comparing 24-h urinalysis of hypertensive and normotensive individuals demonstrated decreased levels of citrate excretion in hypertensives. Citrate is thought to be protective against stone formation, and therefore a reduction in citrate excretion may lead to higher rates of KSD in people suffering from HT [25]. Kohjimoto et al. also demonstrated that in the Japanese population, HT was a risk factor for nephrolithiasis independent of age, sex and other MetS components [24].

Whilst the above studies have demonstrated that HT is a risk factor for developing kidney stones, two prospective cohort studies have argued that it may be confounded by other components of MetS such as increased BMI [26, 27]. A potential mechanism by which HT increases an individual's risk of KSD has yet to be described, and this relationship may in fact be bidirectional in nature, with stone formers also developing HT as a consequence of their KSD, although this is debatable [27].

\section{Dyslipidaemia}

Dyslipidaemia, one of the diagnostic criteria for MetS, is also thought to contribute towards the formation of 
kidney stones through renal lipotoxicity. Lipotoxicity is defined as fat accumulation in non-adipose tissues. It is thought that the accumulation of non-esterified fatty acids in renal cells (specifically proximal tubular cells) may interfere with cell metabolism and consequently reduce ammonia output $[28,29]$. As with reduced ammonia secretion associated with insulin resistance, this results in acidification of urine which is considered to be a core component of the pathophysiology of uric acid stone formation. However, this process is yet to be demonstrated in humans [28]. Patients with a lower urinary $\mathrm{pH}$ associated with low HDL have been observed to have higher levels of uric acid, oxalate and sodium on 24-h urinalysis [30], which may contribute to their risk of developing KSD. In addition to lipotoxicity, an alternative mechanism is that HDL may be protective against the development of insulin resistance [31]; hence, reduction in HDL increases risk of insulin resistance and therefore risk of KSD.

\section{Management}

The proposed management of kidney stones in the obese patient ranges from patient-led lifestyle modifications to pharmacological management and invasive intervention. Management plans should be tailored to individual patients and may well be influenced by their BMI and the presence of MetS.

\section{Acute Management}

Patients with acute renal colic should have appropriate analgesia given in the first instance. Non-steroidal anti-inflammatory drugs are the preferred class of analgesics and are shown to be more effective than opioids for managing renal colic discomfort [32], with parenteral diclofenac often being cited as the medication of choice [33].

In addition to pain relief, increasing fluid intake is another conservative management option in KSD. A high fluid intake will lead to an increase in urinary production and therefore an increase in hydrostatic pressure proximal to the stone, thereby increasing peristalsis and the likelihood of spontaneous stone passage [34]. Various pharmacological adjuncts such as $\alpha$-blockers or calcium channel blockers can also be used to try and increase spontaneous passage and potentially to reduce colic episodes [32]. However, with increasing stone sizes, spontaneous passage is unlikely, and therefore other options of management should be considered [32].
Interventional Management

EAU (European Association of Urology) guidelines suggest active retrieval of stones should be considered in the following circumstances [35]: when the likelihood of spontaneous stone passage is low, the patient is experiencing pain that is resistant to pharmacological management and renal insufficiency or obstruction as a consequence of the stone. Shock wave lithotripsy (SWL), flexible ureteroscopy (fURS) and percutaneous nephrolithotomy (PCNL) are all potential methods of stone management.

SWL uses high-energy acoustic shock waves externally to fragment the stone thus enabling its passage down the urinary tract. Due to the non-invasive nature of this option, it quickly gained favour. SWL is a recommended treatment for stones that are $\leq 20 \mathrm{~mm}$ in diameter [35]. However, SWL is contraindicated in pregnancy, bleeding disorders and the presence of an uncontrolled UTI [35]. The major complication associated with SWL includes renal haematoma, steinstrasse, secondary colic and urinary tract infections [36].

SWL in adults does not require a general anaesthetic and therefore removes the associated increased risk with anaesthesia and increased BMI. However, although SWL is often a preferred first-line treatment, the success rate of this procedure is reduced in obese patients. In a study comparing the outcomes of SWL in morbidly obese patients (BMI $\geq 40 \mathrm{~kg} / \mathrm{m}^{2}$ ) and non-obese patients $\left(\mathrm{BMI}<30 \mathrm{~kg} / \mathrm{m}^{2}\right)$, the stone-free rate (SFR) was $82 \%$ in non-obese patients compared with $67 \%$ in the morbidly obese group, and $32 \%$ of the obese group required further procedures compared with only $8 \%$ of the nonobese group [37॰]. The lower success rate is believed to be due to an increase in skin to stone distance which leads to increased absorption of the shock wave, difficulty in stone localisation and radiolucency of urate stones, and therefore inability to focus the shock wave beam effectively [37•]. In addition to this, an increase in BMI is associated with an increased likelihood of residual stone fragments being present post SWL compared to being stone free post SWL [38], and this was also demonstrated by Thomas and Cass who detected a SFR of $68 \%$ in obese patients [39]. A BMI $>30 \mathrm{~kg} / \mathrm{m}^{2}$ was also associated with an increased risk of renal haematoma [36], possibly due to inappropriately high energy usage. One hypothesis that may explain the increase in postoperative haematomas is that many of these patients have concurrent HT and increased vascular vulnerability. HT has been shown to increase the risk of haematomas in multiple studies [36, 40]; however, the literature is not conclusive.

Flexible ureterorenoscopy (FURS) is an alternative first-

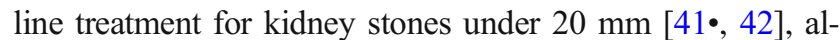
though for lower pole stones, FURS is considered the preferred treatment option [35, 43, 44]. FURS is a minimally invasive endoscopic procedure that uses lasers to fragment kidney stones found in the urinary tract. Modern complication 
rates associated with FURS are around 9\%, with the most serious complications (Clavien $\geq$ III) making up $<1 \%$ [35]. One study demonstrated reduced re-treatment rates when URS was used in comparison to SWL for renal pelvis stones in obese patients $(9.5 \%$ vs $36 \%, p<0.001)$. In another study, the 3-month SFR was also significantly better in FURStreated patients $(90.4 \%$ vs $68 \%, p<0.001)$, with no significant difference in the complication rates between the two groups (FURS $14.2 \%$, SWL 20\%; $p=0.211$ ) [45]. The lower SFR observed in patients treated with SWL is likely because the stone fragments may remain after SWL and these often form a nidus for stone re-growth [45].

A study looking at the impact of BMI on the outcome of FURS treatment showed that there was no significant difference in the outcomes (SFR, complications) of obese patients compared to normal-weight patients [ $41 \bullet$ ]. However, in a subanalysis, FURS had poorer SFR in obese patients for stones $>20 \mathrm{~mm}$ [46]. However, multiple further studies have found no difference in SFR with URS for normal-weight patients (60.8-70.7\%) compared with obese patients (6579.4\%) [47-49], even for large stone sizes (>20 mm) [48]. There was also no significant difference between complication rates for normal-weight patients and obese patients [47, 49]. A systematic review of 131 obese patients across 7 studies evaluating the effectiveness and safety profile of URS demonstrated a SFR of $87.5 \%$ and a complication rate of $11.4 \%$ [42]. Another systematic review looking at 835 patients over 15 studies demonstrated a SFR of $82.5 \%$ after URS in patients with a high BMI, with the SFR being $85.2 \%$ for obese patients and $80.4 \%$ for morbidly obese patients. This same study calculated a complication rate of $9.3 \%$, with the majority of complications being either grade I or II with no associated mortality [41 ${ }^{\bullet}$. Therefore, URS can be considered a procedure both efficacious and safe in obese patients.

Finally, standard or minimally invasive percutaneous nephrolithotomy (PCNL) is the treatment of choice for stones $>20 \mathrm{~mm}$ in size [35]. Complications include postoperative fever, bleeding, urinary leakage and organ injury [35], with prophylactic antibiotic therapy perioperatively having been shown to reduce the risk of postoperative fever [35].

A case-control analysis that matched 97 morbidly obese patients (BMI $>40 \mathrm{~kg} / \mathrm{m}^{2}$ ) with 97 normal-weight patients demonstrating a significant impact of BMI on PCNL outcomes [50]. This study showed that SFR decreased with an increase in BMI and this was associated with a higher risk of re-intervention. Operative time was higher in morbidly obese patients, and these patients were also more likely to experience complications ( $22 \%$ vs $6 \%$, $p=0.004$ ) [50]. However, these findings have been contradicted by multiple other studies. A retrospective study of 114 patients found that BMI was statistically independent when looking at SFR, length of hospital stay and complication rates [51]. Similarly, a multivariate analysis comparing the outcomes of 225 patients stratified into four separate BMI groups (normal, overweight, obese and morbidly obese) showed no significant impact of BMI on SFR, complication rate, hospital stay or intraoperative blood loss [52]. However, it did find a longer procedure time and radiation exposure in obese patients [52]. These findings that BMI only has a limited impact were corroborated by a systematic review and metaanalysis of 7 studies where no significant difference in complication rate, SFR and length of hospital stay was seen, although morbidly obese patients did have a longer operation time [52]. Most current evidence is based on observational studies; therefore, more randomised control trials are required to demonstrate outcomes of PCNL in this group.

\section{Ongoing Management}

As discussed above, patients with MetS are at an increased risk of developing kidney stones. It is likely their risk of recurrence is higher, and therefore patient education is important to help them manage their risk of developing stone using conservative measures. Once an episode of nephrolithiasis has been treated and resolved, it is important that steps are taken to help reduce the likelihood of further KSD through mechanisms such as increasing fluid intake to maintain a high 24-h urine output volume. Although no definitive urine output has been demonstrated to reduce the risk of recurrence, $2.5 \mathrm{~L}$ is considered to be a reasonable target [53]. In addition, dietary modification is another conservative measure, and depending on stone composition, restriction of dietary oxalate has shown to be effective at reducing recurrence [53].

Patients with calcium stones and high urinary calcium should be counselled on reducing calcium intake. Those found having calcium stones and a low urinary $\mathrm{pH}$ should be advised to increase citrate consumption in the form of fruit and vegetables in an effort to increase their urinary $\mathrm{pH}$ and reduce the risk of stone formation [53]. Thiazide diuretics have been shown to reduce calcium excretion in the urine and therefore are a suitable treatment for calcium stone formers as per EAU and American Urological Association (AUA) guidelines [53, 54]. Potassium citrate should be offered to calcium stone formers with a low $\mathrm{pH}$ on urinalysis to help raise the $\mathrm{pH}$ and prevent calcium oxalate aggregation [53, 54], and potassium citrate is preferable to sodium citrate as it does not increase urinary calcium excretion [53]. Pharmacological management is often only indicated when abnormalities in 24-h urinary biochemistry are detected. In the case of urate stone formation, the first-line 
pharmacological treatment would be to increase urinary $\mathrm{pH}$ and alkalinize the urine $[53,54]$.

\section{Conclusion}

Obesity and metabolic syndrome are demonstrable risk factors for the development of kidney stones. Whilst it is important that MetS is investigated in patients presenting with KSD, it is also necessary to optimise medical and surgical management. Currently, flexible ureteroscopy seems to be the most appropriate intervention for small stones and PCNL for larger stones in the obese population. However, randomised trials are needed to clarify the most appropriate surgical management for these patients.

\section{Compliance with Ethical Standards}

Conflict of Interest Claire Kelly declares no potential conflicts of interest. Robert M. Geraghty reports part of his salary is paid by Health Education England. Bhaskar K. Somani is a section editor for Current Urology Reports.

Human and Animal Rights and Informed Consent This article does not contain any studies with human or animal subjects performed by any of the authors.

Open Access This article is distributed under the terms of the Creative Commons Attribution 4.0 International License (http:// creativecommons.org/licenses/by/4.0/), which permits unrestricted use, distribution, and reproduction in any medium, provided you give appropriate credit to the original author(s) and the source, provide a link to the Creative Commons license, and indicate if changes were made.

\section{References}

Papers of particular interest, published recently, have been highlighted as:

- Of importance

1. Boyce CJ, Pickhardt PJ, Lawrence EM, et al. Prevalence of urolithiasis in asymptomatic adults: objective determination using low dose noncontrast computerized tomography. J Urol. 2010;183: 1017-21.

2. Edvardsson VO, Indridason OS, Haraldsson G, et al. Temporal trends in the incidence of kidney stone disease. Kidney Int. 2013;83:146-52.

3. Yasui T, Iguchi M, Kohri K, et al. Prevalence and epidemiological characteristics of urolithiasis in Japan: national trends between 1965 and 2005. Urology. 2008;71(2):209-13.

4. Antonelli JA, Maalouf NM, Pearle MS, et al. Use of the National Health and Nutrition Examination Survey to calculate the impact of obesity and diabetes on cost and prevalence of urolithiasis in 2030 . Eur Urol. 2014:724-9.

5. Eckel RH, Grundy SM, Zimmet PZ. The metabolic syndrome. Lancet (London, England). 2005;365(9468):1415-28.
6. Wang YC, McPherson K, Marsh T, et al. Obesity 2 Health and economic burden of the projected obesity trends in the USA and the UK. Lancet. 2011:815-25.

7. Alberti KG, Eckel RH, Grundy SM, Zimmet PZ, Cleeman JI, Donato KA, et al. Harmonizing the metabolic syndrome: a joint interim statement of the International Diabetes Federation Task Force on Epidemiology and Prevention; National Heart, Lung, and Blood Institute; American Heart Association; World Heart Federation; International Atherosclerosis Society; and International Association for the Study of Obesity. Circulation. 2009;120(16):1640-5.

8. Grundy SM. Metabolic syndrome update. Trends Cardiovasc Med. 2016;26(4):364-73.

9. Pastore AL, Tasca A, De Nunzio C, et al. Obesity and kidney stone disease: a systematic review. Minerva Urol Nefrol. 2018;70(4): 393-400.

10. Ikramuddin S, Buchwald H. How bariatric and metabolic operations control metabolic syndrome. Br J Surg. 2011;98(10):1339-41.

11. Grundy SM. Adipose tissue and metabolic syndrome: too much, too little or neither. Eur J Clin Invest. 2015;45:1209-17.

12. Pearle MS, Calhoun EA, Curhan GC. Urologic diseases in America project: urolithiasis. J Urol. 2005;173(3):848-57.

13. Rukin NJ, Siddiqui ZA, Chedgy ECP, Somani BK. Trends in upper tract stone disease in England: evidence from the hospital episodes statistics database. Urol Int. 2017;98(4):391-6.

14. Daudon M, Lacour B, Doré JC, et al. Changes in stone composition according to age and gender of patients: a multivariate epidemiological approach. Urol Res. 2004;32(3):241-7.

15. Taylor EN, Stampfer MJ, Curhan GC, et al. Obesity, weight gain, and the risk of kidney stones. JAMA. 2005;293(4):455-62.

16. Curhan GC, Willett WC, Rimm EB, Speizer FE, Stampfer MJ. Body size and risk of kidney stones. J Am Soc Nephrol. 1998;9(9):1645-52.

17. Zhou T, Watts K, Agalliu I, et al. Effects of visceral fat area and other metabolic parameters on stone composition in patients undergoing percutaneous nephrolithotomy, 2013:1416-1420.

18. Scales CD Jr, Smith AC, Hanley JM, et al. Prevalence of kidney stones in the United States; 2012. p. 160-5.

19. Nowfar S, Palazzi-Churas K, Sur RL, et al. The relationship of obesity and gender prevalence changes in United States inpatient nephrolithiasis. Urology. 2011;78(5):1029-33.

20. Kadlec AO, Greco K, Fridirici ZC, Hart ST, Vellos T, Turk TM Metabolic syndrome and urinary stone composition: what factors matter most? Urology. 2012;80(4):805-10.

21. Kabeya Y, Kato K, Tomita M, et al. Associations of insulin resistance and glycemic control with the risk of kidney stones. Intern Med. 2012;51:699-705.

22. Weinberg AE, Patel CJ, Chertow GM, Leppert JT. Stone disease: diabetic severity and risk of kidney stone disease. Eur Urol. 2014;65:242-7.

23. Spatola L, Ferraro PM, Gambaro G, et al. Metabolic syndrome and uric acid nephrolithiasis: insulin resistance in focus. Metabolism. 2018;83:225-33.

24. Kohjimoto Y, Sasaki Y, Iguchi M, Matsumura N, Inagaki T, Hara I. Association of metabolic syndrome traits and severity of kidney stones: results from a nationwide survey on urolithiasis in Japan. Am J Kidney Dis. 2013;61(6):923-9.

25. Hartman C, Moreira DM, Leavitt DA, et al. Does hypertension impact 24-hour urine parameters in patients with nephrolithiasis? Urology. 2015;85(3):539-43.

26. Madore F, Stampfer MJ, Willett WC, Speizer FE, Curhan GC. Nephrolithiasis and risk of hypertension in women. Am J Kidney Dis. 1998;32(5):802-7.

27. Cappuccio FP, Siani A, Barba G, Mellone MC, Russo L, Farinaro $\mathrm{E}$, et al. A prospective study of hypertension and the incidence of kidney stones in men. J Hypertens. 1999;17(7):1017-22. 
28. Bobulescu IA, Dubree M, Zhang J, McLeroy P, Moe OW. Effect of renal lipid accumulation on proximal tubule $\mathrm{Na}+\mathrm{H}+$ exchange and ammonium secretion. Am J Physiol Ren Physiol. 2008;294(6): F1315-F22.

29. Bobulescu IA. Renal lipid metabolism and lipotoxicity. Curr Opin Nephrol Hypertens. 2010;19(4):393-402.

30. Torricelli FCM, De SK, Gebreselassie S, et al. Dyslipidemia and kidney stone risk; 2014. p. 667-72.

31. Hoofnagle AN, Vaisar T, Mitra P, Chait A. HDL lipids and insulin resistance. Curr Diab Rep. 2010;10(1):78-86.

32. Türk C, Petř́ik A, Sarica K, Seitz C, Skolarikos A, Straub M, et al. EAU guidelines on diagnosis and conservative management of urolithiasis. Eur Urol. 2016;69(3):468-74.

33. Royal New Zealand College of General Practioners. Managing patients with renal colic in primary care: know when to hold them. Best Practice J New Zealand 2014;60:8-17.

34. Seitz C, Liatsikos E, Porpiglia F, et al. Medical therapy to facilitate the passage of stones: what is the evidence?, 2009:455-471.

35. Türk C, Petř́k A, Sarica K, Seitz C, Skolarikos A, Straub M, et al. EAU guidelines on interventional treatment for urolithiasis. Eur Urol. 2016;69(3):475-82.

36. Nussberger F, Roth B, Metzger T, et al. A low or high BMI is a risk factor for renal hematoma after extracorporeal shock wave lithotripsy for kidney stones. Urolithiasis. 2017;45:317-21.

37. Dede O, Șener NC, Baș O, et al. Does morbid obesity influence the success and complication rates of extracorporeal shockwave lithotripsy for upper ureteral stones? Turk Uroloji Dergisi. 2015;41(1):20-3 This paper demonstrates that SWL may not be an appropriate treatment for KSD in obese patients due to lower success rates and an increase in requirement for subsequent procedures.

38. Pareek G, Armenakas NA, Panagopoulos G, et al. Extracorporeal shock wave lithotripsy success based on body mass index and hounsfield units. Urology. 2005;65:33-6.

39. Thomas R, Cass AS. Extracorporeal shock wave lithotripsy in morbidly obese patients. J Urol. 1993;150(1):30-2.

40. H-y L, Yang Y-H, Shen J-T, et al. Risk factors survey for extracorporeal shockwave lithotripsy-induced renal hematoma. J Endourol. 2013;27:763-7.

41. Ishii H, Couzins M, Aboumarzouk O, et al. Outcomes of systematic review of ureteroscopy for stone disease in the obese and morbidly obese population. J Endourol. 2016;30:135-45 A systematic review that demonstrates that there is no difference in the safety or efficacy of FURS as a treatment for KSD when comparing obese patients with those of a normal BMI.

42. Aboumarzouk OM, Somani B, Monga M. Safety and efficacy of ureteroscopic lithotripsy for stone disease in obese patients: a systematic review of the literature. BJU Int. 2012;110(8 Pt B):E374-80.
43. Donaldson JF, Lardas M, Scrimgeour D, Stewart F, MacLennan S, Lam TBL, et al. Systematic review and meta-analysis of the clinical effectiveness of shock wave lithotripsy, retrograde intrarenal surgery, and percutaneous nephrolithotomy for lower-pole renal stones. Eur Urol. 2015;67(4):612-6.

44. Scales CD Jr, Lai JC, Dick AW, et al. Comparative effectiveness of shock wave lithotripsy and ureteroscopy for treating patients with kidney stones. JAMA Surg. 2014;149:648-53.

45. Javanmard B, Razaghi MR, Jafari AA, et al. Flexible ureterorenoscopy versus extracorporeal shock wave lithotripsy for the treatment of renal pelvis stones of $10-20 \mathrm{~mm}$ in obese patients. J Lasers Med Sci. 2015;6(4):162-6.

46. Doizi S, Letendre J, Bonneau C, et al. Comparative study of the treatment of renal stones with flexible ureterorenoscopy in normal weight, obese, and morbidly obese patients. Urology. 2015;85:3844.

47. Sari E, Tepeler A, Yuruk E, et al. Effect of the body mass index on outcomes of flexible ureterorenoscopy. Urolithiasis. 2013;41:499504.

48. Caskurlu T, Atis G, Arikan O, Pelit ES, Kilic M, Gurbuz C. The impact of body mass index on the outcomes of retrograde intrarenal stone surgery. Urology. 2013;81(3):517-21.

49. Delorme G, Huu YN, Lillaz J, Bernardini S, Chabannes E, Guichard G, et al. Ureterorenoscopy with holmium-yttriumaluminum-garnet fragmentation is a safe and efficient technique for stone treatment in patients with a body mass index superior to $30 \mathrm{~kg} / \mathrm{m}^{2}$. J Endourol. 2012;26(3):239-43.

50. Fuller A, Razvi H, Denstedt JD, et al. The Clinical Research Office of the Endourological Society percutaneous nephrolithotomy global study: outcomes in the morbidly obese patient - a case control analysis. Can Urol Assoc J. 2014;8(5-6 JUNE):E393-E97.

51. Alyami FA, Skinner TAA, Norman RW. Impact of body mass index on clinical outcomes associated with percutaneous nephrolithotomy. Can Urol Assoc J. 2013;7:E197-201.

52. Torrecilla Ortiz C, Meza Martinez AI, Vicens Morton AJ, et al. Obesity in percutaneous nephrolithotomy. Is body mass index really important? Urology. 2014;84:538-42.

53. Pearle MS, Goldfarb DS, Assimos DG, Curhan G, Denu-Ciocca CJ, Matlaga BR, et al. Medical management of kidney stones: AUA guideline. J Urol. 2014;192:316-24.

54. Skolarikos A, Straub M, Knoll T, et al. Metabolic evaluation and recurrence prevention for urinary stone patients: EAU guidelines. Eur Urol. 2015;67:750-63.

Publisher's Note Springer Nature remains neutral with regard to jurisdictional claims in published maps and institutional affiliations. 